\title{
Dispositional optimism, optimism priming, and prevention of ego depletion
}

Citation for published version (APA):

Den Bosch-Meevissen, Y. M. C. I., Peters, M. L., \& Alberts, H. J. E. M. (2014). Dispositional optimism, optimism priming, and prevention of ego depletion. European Journal of Social Psychology, 44(6), 515520. https://doi.org/10.1002/ejsp.2055

Document status and date:

Published: 01/10/2014

DOI:

10.1002/ejsp.2055

Document Version:

Publisher's PDF, also known as Version of record

Document license:

Taverne

Please check the document version of this publication:

- A submitted manuscript is the version of the article upon submission and before peer-review. There can be important differences between the submitted version and the official published version of record.

People interested in the research are advised to contact the author for the final version of the publication, or visit the DOI to the publisher's website.

- The final author version and the galley proof are versions of the publication after peer review.

- The final published version features the final layout of the paper including the volume, issue and page numbers.

Link to publication

\footnotetext{
General rights rights.

- You may freely distribute the URL identifying the publication in the public portal. please follow below link for the End User Agreement:

www.umlib.nl/taverne-license

Take down policy

If you believe that this document breaches copyright please contact us at:

repository@maastrichtuniversity.nl

providing details and we will investigate your claim.
}

Copyright and moral rights for the publications made accessible in the public portal are retained by the authors and/or other copyright owners and it is a condition of accessing publications that users recognise and abide by the legal requirements associated with these

- Users may download and print one copy of any publication from the public portal for the purpose of private study or research.

- You may not further distribute the material or use it for any profit-making activity or commercial gain

If the publication is distributed under the terms of Article $25 \mathrm{fa}$ of the Dutch Copyright Act, indicated by the "Taverne" license above, 


\title{
Fast track report \\ Dispositional optimism, optimism priming, and prevention of ego depletion
}

\author{
YVO M. C. IN DEN BOSCH-MEEVISSEN*, MADELON L. PETERS AND HUGO J. E. M. ALBERTS \\ Clinical Psychological Science, Maastricht University, Maastricht, The Netherlands
}

\begin{abstract}
Exerting self-control leads to a diminished capacity to carry out successive acts of self-control, a process termed ego depletion. The present study investigated whether dispositional optimism, priming of an optimistic orientation, or their interaction can counteract the ego depletion effect. A total of 160 participants performed a self-control-demanding weight-lifting task on two occasions. Half of the participants were depleted between the two weight-lifting tasks. Because depletion of self-regulatory resources can undermine optimism half of the participants in the depletion, and no-depletion condition were primed for an optimistic orientation before performing the second self-control task. Results demonstrated an interaction between dispositional optimism and optimism priming. Only in participants high in dispositional optimism did the optimism prime lead to undiminished persistence on the weight-lifting task. These results demonstrate that dispositional optimism may lead to improved goal persistence in the face of adversity only under conditions in which optimistic schemas are activated. Copyright (C) 2014 John Wiley \& Sons, Ltd.
\end{abstract}

The ability to carry out self-control-the voluntary act of suppressing an impulse or overriding a habitual dominant response- has over the past years repeatedly been associated with more desirable life circumstances (e.g., Finkel \& Campbell, 2001; Mischel, Shoda, \& Peake, 1988; Tangney, Baumeister, \& Boone, 2004). In contrast, failure to carry out self-control has been linked to more pathological and dysfunctional states (e.g., Burton, Cullen, Evans, Alarid, \& Dunaway, 1998; LaGrange \& Silverman, 1999; Vazsonyi, Pickering, Junger, \& Hessing, 2001).

According to the limited strength model, proposed by Muraven and Baumeister (2000) and Vohs and Heatherton (2000), repeated acts of self-control draw from a limited general resource that, upon depletion, results in reduced capacity for continued self-regulation, a process termed ego depletion (Baumeister, Bratslavsky, Muraven, \& Tice, 1998). The ego depletion effect has been demonstrated numerous times in controlled experimental studies using a dual-task paradigm (Hagger, Wood, Stiff, \& Chatzisarantis, 2010). An initial task requiring self-control results in reduced performance on a subsequent (unrelated) task requiring self-control.

There are stable individual differences in self-regulatory capacity (Hoyle, 2006), and these differences may moderate the ego depletion effect (Baumeister, Gailliot, DeWall, \& Oaten, 2006). One important individual difference variable in this respect could be optimism, that is, the global expectation that good things will happen in the future. Optimism has been shown to have a substantial impact on an individual's ability to cope with adversity. Optimistic individuals are more inclined to use approach coping strategies that are aimed at eliminating or managing stressors (Carver, Scheier, \& Segerstrom, 2010;
Solberg Nes \& Segerstrom, 2006) and show increased goal persistence (Segerstrom, 2007; Solberg Nes, Evans, \& Segerstrom, 2009). Similarly, they may be more willing to carry out self-control in order to pursue their goals even when their resources are depleted. In addition, optimism is related to higher levels of positive affect (Carver et al., 2010), and positive affect has previously been shown to restore self-control performance after depletion (Tice, Baumeister, Shmueli, \& Muraven, 2007).

However, generating and maintaining optimistic beliefs may itself require self-control resources (Fischer, Greitemeyer, \& Frey, 2007). In a series of experiments, Fischer et al. (2007) showed that depleted participants exhibited less optimism regarding their own abilities, less optimistic future expectancies, and had more difficulty in retrieving positive information about the self than nondepleted participants. Thus, depletion of self-regulatory resources may actually undermine optimism. Other studies similarly demonstrated that ego depletion can diminish the link between traits that are aimed at regulating behavior and actual behavioral outcomes (Baumeister et al., 2006). In line with this, Solberg Nes, Carlson, Crofford, de Leeuw, and Segerstrom (2011) recently showed that participants with high dispositional optimism persisted longer on an unsolvable anagram task when they were not depleted but not after prior depletion. Thus, depletion of self-regulatory resources may offset the beneficial effects of optimism on behavioral persistence.

The present study was meant as a further examination of the hypothesis that optimism might be able to counteract the ego depletion effect. First, the finding that optimism does not lead to improved performance after depletion is in need of 
replication using a more traditional ego depletion design. The study of Solberg Nes et al. (2011) made use of secondary analyses of existing data, and the depletion effect was not directly measured within individual participants, that is, there was no predepletion assessment of persistence. Moreover, the primary outcome of the study was time spent on trying to solve an unsolvable anagram, which meant that increased persistence did not lead to better outcome. The present study adopted a design that is more common in ego depletion studies in which exerting self-control is functional (i.e., persistence leads to better outcome) and in which the degree of performance decrements after depletion can be directly established within an individual. Self-control was measured by means of persistence on a physical performance task: lifting a 1.5 -kg weight as long as possible. After establishing each individual's baseline level of performance, half of the participants performed a depleting cognitive task while the other half performed a nondepleting cognitive task. Next, all participants again performed the weight-lifting task. The degree of depletion was assessed by the decrease in lifting time from the first to the second task performance.

Second, we explored whether priming optimism after depletion might be instrumental in maintaining undiminished self-control performance. In order to prime optimism, we used a scrambled sentence task that has previously been shown to successfully increase optimism (Fosnaugh, Geers, \& Wellman, 2009). If depletion of self-regulatory resources indeed undermines an individual's habitual optimistic orientation, optimism priming might be able to restore and normalize an individual's level of optimism by making optimistic schemas more readily available again. This would lead to the prediction that especially the combination of a high level of dispositional optimism and optimism priming would be associated with better self-control performance after depletion. Alternatively, optimism priming could also in itself improve self-control performance after depletion. Previous studies found persistence priming (Alberts, Martijn, Greb, Merckelbach, \& de Vries, 2007; Martijn et al., 2007) and priming of positive emotions (Ren, Hu, Zhang, \& Huang, 2010) to be able to counteract the ego depletion effect.

In conclusion, the present study examined whether dispositional optimism, optimism priming, or their interaction can offset the ego depletion effect. The primary hypothesis is that there will be an interaction between dispositional optimism and optimism priming: Individuals high on dispositional optimism who are primed with optimism words after a cognitive depleting task show the least deterioration of persistence on a physical performance test. As secondary and alternative hypotheses, we will examine whether dispositional optimism or optimism priming have a main effect on depletion of selfregulatory performance.

\section{METHODS}

\section{Participants}

A total of 160 female undergraduate students of the University of Maastricht with ages ranging from 18 to 47 years $(M=22.7$,
$S D=4.9)$ participated in this study. Participants were block randomized to one of four conditions: depletion-optimism priming; depletion-neutral priming; no depletion-optimism priming; and no depletion-neutral priming, with 40 participants per condition. Each participant was individually tested in a 45-min session and received a monetary reward for participation. The experiment was approved by the Ethical Committee of the Faculty of Psychology and Neuroscience.

\section{Manipulations}

\section{Depletion Induction}

Tasks that have been demonstrated to be depleting require effortful suppression of an impulse, overriding of a habitual or dominant response, or involve complex cognitive processing (Hagger et al., 2010). The present study used a challenging attention regulation task, which has repeatedly been shown to have depleting effects (e.g., Alberts et al., 2007; Alberts, Martijn, \& de Vries, 2011). Participants in the depletion condition were exposed to relatively difficult calculations with auditory interference, whereas participants in the no-depletion condition were given easy calculations without auditory interference. More specifically, the depletion task required participants to mentally solve relatively difficult mathematical problems (e.g., $26+33+46$ ) as fast and accurately as possible during a period of $8 \mathrm{~min}$. Throughout the task, auditory interference in the form of random two-digit numbers was presented through headphones. The nondepletion task differed only in that the mathematical problems were relatively easy (e.g., $2+5+3$ ), and there was no auditory interference.

\section{Optimism Priming}

To prime optimism, a scrambled sentence task was used (Fosnaugh et al., 2009). The task presented 15 strings of five words, four of which were needed to form a correct sentence when put in the right order. In the neutral version of the task, only neutral words were included (e.g., rain and magazine). In the optimism version of the task, 11 items contained an optimism-related word (e.g., hope, confidence, and optimistic) that needed to be used to construct a correct sentence. Participants were instructed to read the answers out aloud and respond in a brisk pace. Fosnaugh et al. (2009) previously demonstrated that the optimism version of this task led to an immediate increase in optimism levels.

\section{Measures}

\section{Self-control}

A weight-lifting task was used as a measure of self-control. Physical exercise tasks have successfully been used to measure self-control in previous research (e.g., Alberts et al., 2007; Ciarocco, Sommer, \& Baumeister, 2001). By lifting a weight, muscles become fatigued and even painful, which results in the urge to stop lifting. Overcoming this fatigue and overriding the urge to quit requires self-control. Moreover, a physical exercise task is a relatively inconspicuous measure of self-control as most people think that weight lifting primarily depends on muscular 
strength and endurance. The weight-lifting task required participants to sit upright in a chair and hold a $1.5-\mathrm{kg}$ weight with their dominant arm stretched at a $90^{\circ}$ angle in front of them as long as possible. Persistence time was measured in seconds from the moment of lifting the weight until the weight dropped less than a 5-cm margin, which activated a buzzer (cf. Alberts et al., 2007).

\section{Optimism}

Dispositional optimism was measured using a Dutch translation of the life orientation test-revised (LOT-R; Scheier, Carver, \& Bridges, 1994). The LOT-R consists of 10 statements, three of which are positively phrased, three are negatively phrased, and four are filler items. All items are rated along a 5 -point continuum ( 0 , strongly disagree, to 4 , strongly agree). A total LOT-R score is obtained by summation of the scores on the three positively phrased items and the reversed scores on the three negatively phrased items, higher scores reflecting higher levels of optimism. In the present sample, a Cronbach's alpha of .74 was obtained for the LOT-R total score.

The subjective probability test (SPT; Macleod, 1996) was included as a more state-like measure of optimism. The SPT consists of 10 statements reflecting positive expectancies for the future (SPT-pos; e.g., "you will have many friends") and 20 statements reflecting negative expectancies for the future (SPTneg; e.g., "you will have health problems"). Participants rate the likelihood of each event on a 7-point scale (1, not at all likely to occur, to 7, extremely likely to occur). In the present study, a Cronbach's alpha of .83 for the positive items and .93 for the negatively items was obtained. Recent studies demonstrated the SPT to be sensitive to brief optimism manipulations (Meevissen, Peters, \& Alberts, 2011; Peters, Flink, Boersma, \& Linton, 2010).

\section{Affect}

Trait affect was measures by the trait version of the Positive and Negative Affect Schedule (PANAS; Watson, Tellegen, \& Clark, 1988), whereas changes in affect during the experiment were measured with the state version of PANAS. PANAS presents 10 positive and 10 negative mood states. Participants rated the frequency with which these mood states are experienced in general (trait version) or the degree to which they are experiences at that moment (state version), both on a 5-point scale (1, not at all, to 5, extremely). A sum score was obtained by calculating the mean score of the 10 positive items (PA) and the 10 negative items (NA). For the trait version, a Cronbach's alpha of .82 was obtained for PA and of .84 for NA.

\section{Fatigue}

To measure changes in subjective levels of fatigue, participants rated their current level of fatigue on a Visual Analog Scale at several occasions during the experiment (VAS; 0, not at all fatigued, to 100 , extremely fatigued).

\section{Self-control Task Impressions}

Several $100 \mathrm{~mm}$ VAS scales were included to measure participant's experiences during the second weight-lifting task.
Perceived pain intensity during the task was measured with the question "how painful was your shoulder during the weightlifting task?" (not at all to extremely painful), and pain tolerance was measured with the question "how easy was it to tolerate potential shoulder pain during the weightlifting task?" (extremely difficult to extremely easy). Finally, four questions were added to assess the extent to which participants found the self-control task to be strenuous, difficult, exhausting, and challenging, all rated on a 5-point scale (1, not at all, to 5, extremely).

\section{Awareness Checks}

In order to warrant the integrity of our study, we asked participants about awareness regarding the depletion manipulation, the optimism manipulation, and the study's purpose.

\section{Procedure}

Participants were screened on back, shoulder, or arm problems in order to prevent physical limitations from influencing the self-control task. One day prior to the lab session, participants completed the LOT-R and the PANAS (trait) through an online website. Upon entering the lab, all participants performed the first self-control task (SC1) and filled out the SPT, PANAS (state), and VAS-Fatigue in order to measure their individual premanipulation baseline scores. Subsequently, participants performed either the depleting or the nondepleting calculation task. To test the potential restorative effects of optimism priming, the depletion manipulation was followed by the scrambled sentence task with either optimism-related words or neutral words. In order to measure the degree of depletion, participants repeated the same self-control task (SC2). Finally, they filled out the SPT and PANAS (state) questionnaires and the additional fatigue, self-control task impressions, and awareness check questions. The lab session took about 40-45 min.

\section{Data Analyses}

In order to prevent outliers from confounding the results and in line with previous studies that also employed physical persistence tasks, we conducted an outlier analysis on the difference scores of the two weight-lifting tasks applying a criterion of $z>2$ (Alberts, Martijn, Nievelstein, Jansen, \& de Vries, 2008; Ciarocco et al., 2001). This led to the exclusion of 11 participants. Additionally, material failure prevented two participants from carrying out the self-control task. The remaining 147 participants were distributed across conditions as follows: $N=36$ in the depletion-optimism, $N=39$ in the depletion-neutral, $N=38$ in the nondepletion-optimism, and $N=34$ in the nondepletion-neutral condition. All analyses were performed on the final sample of 147 participants.

One-way ANOVAs were used to test for baseline differences between the conditions. Whether dispositional optimism and/or optimism priming influenced self-control performance after depletion was examined using multiple linear regression analysis with the second self-control performance as dependent variable, the first self-control performance as control variable, and depletion condition, priming condition, dispositional optimism, and all interactions between these variables as independent variables. If the three-way interaction was nonsignificant, 
it was removed. Next, all nonsignificant two-way interactions were removed. The three-way interaction tests the main hypothesis that dispositional optimism counteracts ego depletion only after being reactivated by priming. The two-way interaction depletion $\times$ dispositional optimism tests the hypothesis that dispositional optimism counteracts the depletion effect, whereas the final one-way interaction, depletion $\times$ priming condition, tests the hypothesis that optimism priming in itself, independent from a priori levels of optimism, reduces ego depletion. Depletion and priming condition were dummy coded with $0=$ no depletion/no priming.

Similar analyses were carried out for the self-report measures, that is, state optimism, state affect, fatigue, and task impressions. State positive and negative affect, positive and negative expectancies, and fatigue were measured twice during the experiment, at baseline and after the second weight-lifting task, and the difference score was used as the dependent variable. Task impressions were only measured once, after the second weight-lifting task.

\section{RESULTS}

None of the participants reported any awareness of the purpose of the manipulations, nor what the study was about. There were no baseline differences between the four conditions in dispositional optimism, trait and state affect, positive and negative expectancies, or fatigue (all $p$ 's $>.10$ ). Baseline self-control performance did not differ across conditions $(p=.86)$. In addition, self-control performance was nearly identical for the first $(M=63.0, S D=31.5 \mathrm{~s})$ and second $(M=63.0, \quad S D=21.7 \mathrm{~s})$ weight-lifting tasks. The correlation between the two assessments was highly positive with $r=.75, p<.001$, indicating that differences in performance at the second assessment were not influenced by extremes in physical exertion at baseline.

\section{Self-control Performance}

Because of a heavily skewed distribution in LOT-R scores, three influential data points were removed on the basis of a conservative Cook's distance $d>.06$. Regressing the second self-control performance on baseline self-control performance, depletion condition, priming condition, dispositional optimism, and all two-way and three-way interactions yielded a significant three-way interaction $(\beta=1.16, p=.011) .{ }^{1}$ Table 1 displays the full model. To further analyze the simple effects, we performed a median split on LOT-R scores, where scores $<16$ were defined as low optimism $(n=62)$ and $>16$ as high optimism $(n=85)$. The three-way interaction was broken down to examine the effects of depletion $\times$ optimism priming in relation to dispositional optimism scores. In low optimistic participants, the depletion $\times$ priming interaction was not significant, whereas the interaction was significant in high optimistic participants (Table 1, lower part). As displayed in Figure 1, depletion led to deteriorated self-control performance in participants with low levels of dispositional optimism independent

${ }^{1}$ The same regression analyses on the original data with outliers led to neither significant interaction effects nor a main effect of depletion, showing that these extreme cases exerted a significant influence on the results.
Table 1. Full regression model showing the effects of depletion, priming condition and level of optimisms, and their interactions on self-control performance

\begin{tabular}{lrr}
\hline & $\beta$ & $p$ \\
\hline Main analyses & & \\
Baseline weight lifting & .781 & $<.001$ \\
Depletion & .615 & .101 \\
Priming & .353 & .297 \\
Dispositional optimism & .196 & .062 \\
Optimism $\times$ depletion & -.942 & .016 \\
Optimism $\times$ priming & -.441 & .209 \\
Depletion $\times$ priming & -.854 & .051 \\
Optimism $\times$ depletion $\times$ priming & 1.162 & .011 \\
Low optimists & & \\
Baseline weight lifting & .840 & $<.001$ \\
Depletion & -.150 & .135 \\
Priming & .040 & .699 \\
Depletion $\times$ priming & .028 & .816 \\
High optimists & & \\
Baseline weight lifting & .678 & $<.001$ \\
Depletion & -.414 & $<.001$ \\
Priming & -.200 & .074 \\
Depletion $\times$ priming & .437 & .002 \\
\hline
\end{tabular}

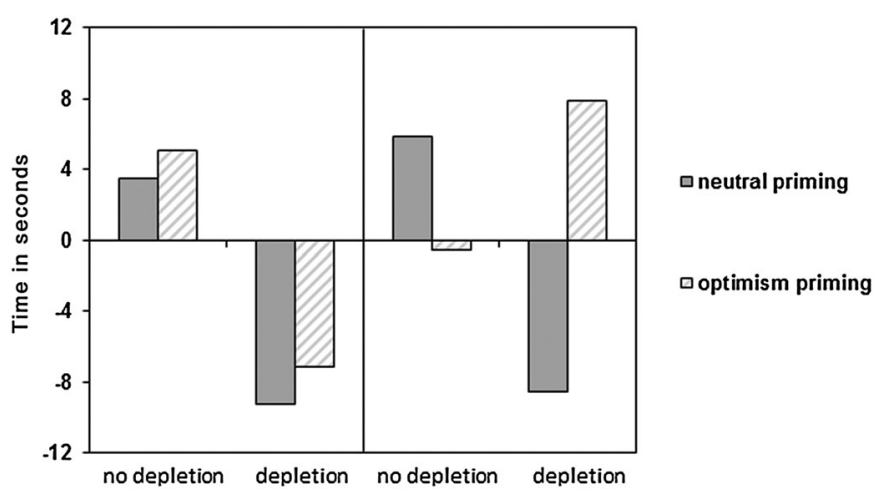

Figure 1. Differences in persistence times (self-control task 2 minus self-control task 1) measured in seconds. Negative scores reflect a premanipulation to postmanipulation reduction in persistence, whereas positive scores reflect an increase in persistence. In general, depletion led to reduced persistence (see depletion $\times$ low dispositional optimism $v s$. no depletion). For participants high in dispositional optimism however, optimism priming reversed this effect. Whereas a neutral prime led to reduced persistence, an optimism prime reversed this effect demonstrated by undiminished persistence (see depletion $\times$ high dispositional optimism)

from priming condition. In other words, low optimistic participants did not benefit from optimism priming. Participants scoring high on dispositional optimism showed a decline in self-control performance after depletion only in the neutral priming condition. However, optimism priming completely offset the ego depletion effect in a priori high optimistic participants, as demonstrated by their undiminished performance on the second weight-lifting task.

\section{Self-control Task Impressions and State Characteristics}

Pain intensity, pain tolerance, strain, difficulty, exhaustiveness, and amount of challenge were in separate analyses regressed on depletion condition, priming condition, dispositional optimism, and all two-way and three-way interactions. 
Nonsignificant terms were removed, first the nonsignificant three-way interaction, followed by nonsignificant two-way interactions, and finally the nonsignificant main effects. For exhaustiveness, a dispositional optimism $\times$ priming condition interaction was found $(\beta=-.41, p=.008)$. After a neutral prime, high optimistic participants reported more exhaustion than low optimistic participants (2.45 vs. 1.95 on a $1-5$ scale); whereas after an optimism prime, high optimistic participants reported less exhaustion (1.94 vs. 2.267). For pain intensity, strain, difficulty, and challenge, main depletion effects were found. Compared with nondepleted participants, depleted participants found the weight-lifting task more painful (60.7 vs. 46.4 on a 100-mm VAS), more strenuous (2.72 vs. 2.41), more difficult (2.09 vs. 1.78), and more challenging (2.49 vs. 2.15). In addition, for pain intensity, an effect of priming condition was found: After optimism priming, the task was experienced as less painful (49.7 vs. 57.4).

Similar analyses were performed for positive and negative expectancies (SPT), positive and negative affect (PANAS), and fatigue at the end of session, using the baseline score of the state characteristics as an additional predictor. The only significant effect was a three-way interaction on negative affect (dispositional optimism $\times$ depletion $\times$ priming: $\beta=.39$, $p=.021$ ), which however was not easily explained by simple effect analyses.

\section{DISCUSSION}

The present study aimed to gain more insight in the influence of optimism on self-control performance when regulatory resources are low. We employed a dual-task paradigm in which participants' self-control performance (weight-lifting task) was measured at baseline and after performing either a depleting or a nondepleting calculation task followed by either an optimism priming task or a neutral task. The primary ego depletion effect was demonstrated once more, as evidenced by the decrease in weight-lifting times after the depleting task. Moreover, this was accompanied by higher self-reported painfulness, strain, difficulty, and challenge of the task, which is also in keeping with previous evidence (Hagger et al., 2010). To examine the influence of optimism, participants were divided into a high and low dispositional optimism groups on the basis of their LOT-R scores. Additionally, after the (non)depleting task and before the second self-control performance, half of the participants received an optimism priming task. Results indicate that priming an optimistic orientation after having engaged in a depleting task fully counteracted the ego depletion effect only in participants with high levels of dispositional optimism. Optimism priming did not prevent the deterioration of performance after depletion in low dispositional participants. Therefore, it appears that neither dispositional optimism nor optimism priming by itself is sufficient to prevent ego depletion from occurring; rather, the priming task seemed to have restored an individual's a priori optimistic orientation, which may have been compromised after depletion.

These results add to the finding of Solberg Nes et al. (2011) showing that dispositional optimism per se does not lead to improved self-control performance after depletion. As previous research indicated, holding and maintaining optimistic beliefs require self-control resources by themselves (Fischer et al., 2007), and the depletion procedure may undermine an individual's habitual level of optimism. Other studies similarly showed that the influence that trait characteristics exert on behavior may be moderated by ego depletion, that is, the influence of traits that are related to increased self-control are attenuated, whereas the influence of traits that are related to more impulsive behaviors are strengthened (Baumeister et al., 2006). However, our findings suggest that under proper circumstances, dispositional optimism can lead to undiminished persistence in demanding and potentially depleting conditions. Priming people with or reminding them of optimistic beliefs may reactivate their preexisting optimistic schemas and make these more readily available.

The self-report measures did not help in elucidating the underlying mechanism of the finding that-under proper circumstances-dispositional optimism can lead to undiminished performance despite self-regulatory depletion. Dispositional optimism and optimism priming did influence self-reported exhaustion, such that after an optimism prime, participants scoring high on dispositional optimism experienced the task as less exhausting. However, this was independent from depletion condition, and moreover, optimistic participants experienced the task as more exhausting after a neutral prime.

One explanation may be that optimists show an increased willingness to invest energy in a demanding task. Moreover, it appears from our result that the increased willingness of high optimistic people to maintain self-control occurs despite experiencing the task as equally painful, difficult, strenuous, and challenging as their low optimistic counterparts. But because optimists see positive outcomes as more attainable even when progress toward a goal gets more difficult, this may motivate them not to withdraw effort (Carver et al., 2010). This interpretation is consistent with recent motivational accounts of ego depletion that states that exerting self-control decreases the motivation to perform a subsequent control-demanding task either because of fatigue or because of the perceived cost that the new task will place on remaining resources (Hagger et al., 2010). However, when motivation for the second self-control task is increased, by providing incentives or increasing the importance of the task, deterioration of performance can be overcome (Muraven \& Slessareva, 2003; Stewart, Wright, Hui, \& Simmons, 2009). To further test this interpretation, future studies should include a measure of task motivation.

A limitation of the present study is that we did not include a proper manipulation check to test the assumption that depletion may undermine optimism and that priming participants with optimism cues can restore their prior level of optimism. We did include the SPT to assess a range of specific positive and negative expectancies for the future. The SPT has previously been shown to be useful as a state measure of optimism (Meevissen et al., 2011; Peters et al., 2010). However, the SPT was administered only twice, first after the initial weightlifting task and subsequently at the end of the session after participants had engaged in the depletion task, the priming task, and the second weight-lifting task. As a result, the SPT was unable to pick up the net effects of depletion (assumed to lower optimism) and of optimism priming (assumed to increase/restore optimism). We therefore base our interpretation 
of the results on previous studies showing the following: (i) ego depletion compromised optimism (Fischer et al., 2007) and (ii) the priming manipulation that was used in the present study led to increased optimism as measured by the LOT-R (Fosnaugh et al., 2009). Nevertheless, future studies should include a measure of (state) optimism at various time points, that is, after each individual manipulation.

In conclusion, the present study suggests that there may be a bidirectional effect between depletion of self-control resources and optimism. Whereas self-control depletion can undermine optimism, high dispositional optimism may lead to undiminished self-control performance despite depletion if the initial optimistic orientation is restored by reactivating a person's a priori optimism schemas.

\section{ACKNOWLEDGEMENTS}

We are grateful to Andrew Geers for providing us with the optimism priming task.

\section{REFERENCES}

Alberts, J. E. M., Martijn, C., \& de Vries, N. K. (2011). Fighting self-control failure: Overcoming ego depletion by increasing self-awareness. Journal of Experimental Social Psychology, 47, 58-62.

Alberts, J. E. M., Martijn, C., Greb, J., Merckelbach, H., \& de Vries, N. K. (2007). Carrying on or giving in: The role of automatic processes in overcoming ego depletion. British Journal of Social Psychology, 46, 383-399.

Alberts, J. E. M., Martijn, C., Nievelstein, F., Jansen, A., \& de Vries, N. K. (2008). Distracting the self: Shifting attention prevents ego depletion. Self and Identity, 7, 322-334.

Baumeister, R. F., Bratslavsky, E., Muraven, M., \& Tice, D. M. (1998). Ego depletion: Is the active self a limited resource? Journal of Personal Social Psychology, 74, 1252-1265.

Baumeister, R. F., Gailliot, M., DeWall, C. N., \& Oaten, M. (2006). Selfregulation and personality: How interventions increase regulatory success, and how depletion moderates the effects of traits on behavior. Journal of Personality, 74, 1773-1892.

Burton, V. S., Cullen, F. T., Evans, T. D., Alarid, L. F., \& Dunaway, R. G. (1998). Gender, self-control, and crime. Journal of Research in Crime and Delinquency, 35, 2-147.

Carver, C. S., Scheier, M. F., \& Segerstrom, S. C. (2010). Optimism. Clinical Psychological Review, 30, 879-889.

Ciarocco, N. J., Sommer, K. L., \& Baumeister, R. F. (2001). Ostracism and ego depletion: The strains of silence. Personal Social Psychological Bulletin, 27, 1156-1163.

Finkel, E. J., \& Campbell, W. K. (2001). Self-control and accommodation in close relationships: An interdependence analysis. Journal of Personality and Social Psychology, 81, 263-277.

Fischer, P., Greitemeyer, T., \& Frey, D. (2007). Ego depletion and positive illusions: Does the construction of positivity require regulatory resources? Personality and Social Psychology Bulletin, 33, 1306-1321.

Fosnaugh, J., Geers, A. L., \& Wellman, J. A. (2009). Giving off a rosy glow: the manipulation of an optimistic orientation. Journal of Social Psychology, 149, 249-263.
Hagger, M. S., Wood, C., Stiff, C., \& Chatzisarantis, N. L. D. (2010). Ego depletion and the strength model of self-control: A meta-analysis. Psychological Bulletin, 136, 495-525.

LaGrange, T. C., \& Silverman, R. A. (1999). Low self-control and opportunity: Testing the general theory of crime as an explanation for gender differences in delinquency. Criminology, 37, 41-72.

Hoyle, R. H. (2006). Personality and self-regulation: Trait and informationprocessing perspectives. Journal of Personality, 74(6), 1507-1526.

MacLeod, A. K. (1996). Affect, Emotional Disorder, and Future-directed Thinking. Cognition \& Emotion, 10, 69-86.

Martijn, C., Alberts, H. J. E. M., Merckelbach, H., Havermans, R., Huijts, A., \& de Vries, N. K. (2007). Overcoming ego depletion: The influence of exemplar priming on self-control performance. European Journal of Social Psychology, 37, 231-238.

Meevissen, Y. M. C., Peters, M. L., \& Alberts, H. J. E. M. (2011). Become more optimistic by imagining a best possible self: Effects of a two week intervention. Journal of Behavioural Therapy and Experimental Psychiatry, 42, 371-378.

Mischel, W., Shoda, Y., \& Peake, P. K. (1988). The nature of adolescent competencies predicted by preschool delay of gratification. Journal of Personality and Social Psychology, 54, 687-696.

Muraven, M., \& Baumeister, R. F. (2000). Self-regulation and depletion of limited resources: Does self-control resemble a muscle? Psychological Bulletin, 2, 247-259.

Muraven, M., \& Slessareva, E. (2003). Mechanisms of self-control failure: Motivation and limited resources. Personality and Social Psychology Bulletin, 29, 894-906.

Peters, M. L., Flink, I. K., Boersma, K., \& Linton, S. J. (2010). Manipulating optimism: Can imagining a best possible self be used to increase positive future expectancies? The Journal of Positive Psychology, 5(3), 204-211.

Ren, J., Hu, L., Zhang, H., Huang, Z. (2010). Implicit positive emotion counteracts ego depletion. Social Behaviour and Personality, 38(7), 919-928.

Scheier, M. F., Carver, C. S., \& Bridges, M. W. (1994). Distinguishing optimism from neuroticism (and trait anxiety, self-mastery, and self-esteem): A reevaluation of the life orientation test. Journal of Personality and Social Psychology, 67, 1063-1078.

Segerstrom, S. C. (2007). Optimism and resources: Effects on each other and on health over 10 years. Journal of Research in Personality, 41, $772-786$

Solberg Nes, L., \& Segerstrom, S. C. (2006). Dispositional optimism and coping: A meta-analytic review. Personality and Social Psychology Review, 10, 235-251.

Solberg Nes, L., Carlson, C. R., Crofford, L. J., de Leeuw, R., \& Segerstrom, S. C. (2011). Individual differences and self-regulatory fatigue: Optimism, conscientiousness, and self-consciousness. Personality and Individual Differences, 50, 475-480.

Solberg Nes, L., Evans, D. R., \& Segerstrom, S. C. (2009). Optimism and college retention: Mediation by motivation, performance, and adjustment. Journal of Applied Social Psychology, 39, 1887-1912.

Stewart, C. C., Wright, R. A., Hui, S.-K. A., \& Simmons, A. (2009). Outcome expectancy as a moderator of mental fatigue influence on cardiovascular response. Psychophysiology, 46, 1141-1149.

Tangney, J. P., Baumeister, R. F., \& Boone, A. L. (2004). High self-control predicts good adjustment, less pathology, better grades, and interpersonal success. Journal of Personality, 72, 271-322.

Tice, D. M., Baumeister, R. F., Shmueli, D., \& Muraven, M. (2007). Restoring the self: Positive affect helps improve self-regulation following ego depletion. Journal of Experimental Social Psychology, 43, 379-384.

Vazsonyi, A. T., Pickering, L. E., Junger, M., \& Hessing, D. (2001). An empirical test of a general theory of crime: A four-nation comparative study of self-control and the prediction of deviance. Journal of Research in Crime and Delinquency, 38, 91-131.

Vohs, K. D., \& Heatherton, T. F. (2000). Self-regulation failure: A resourcedepletion approach. American Psychological Society, 11(3), 249-254.

Watson, D., Tellegen, A., \& Clark, L. (1988). Development and validation of brief measures of positive and negative affect: The PANAS scales. Journal of Personality and Social Psychology, 54, 1063-1070. 